\title{
Poliklinik Başvurularında Fizik Muayene Süresini Uzun Tutmak Antibiyotik Reçete Edilmesini Azaltıyor
}

\section{Longer Time Spent for Patient in Outpatient Setting is Associated with Lower Antibiotic Prescription}

Özge Serçe, Mustafa Bakır

Marmara Üniversitesi Tıp Fakültesi Hastanesi, Pediatrik Enfeksiyon Hastalıklan Anabilim Dall, Istanbul, Türkiye
Yazışma Adresi/Address for Correspondence Dr.Mustafa Bakir Marmara Üniversitesi Tip Fakültesi Hastanesi, Pediatrik Enfeksiyon Hastallkları Anabilim Dall, Istanbul, Türkiye Tel.: +900532508 1418 E-posta:mbaki@@marmara.edu.tr

Geliş Tarihi/Received: 12.02.2013 Kabul Tarihi/Accepted: 24.06.2013 (c) Güncel Pediatri Dergisi, Galenos Yayınevi tarafindan basılmış̧tr.

(c) The Journal of Current Pediatrics, published by Galenos Publishing.

\section{ÖZET}

Giriş: Ulusal akılcı antibiyotik kullanım politikalarının iyileştirilmesine yön vermek amacıyla çocuk doktorları, aile hekimleri ve pratisyen hekimlerin çocuklarda üst solunum yolu enfeksiyonlarında antibiyotik yazma davranışlarını etkileme olasılığı olan sosyokültürel, sosyodemografik ve düşünsel faktörler araştırıldı.

Gereç ve Yöntem: Etik kurul onayı alındıktan sonra ülkenin farklı bölgelerinde çalışan 7421 hekime anketler dağıtıldı. Reçete etme davranışlarııı etkileyen her bir faktörün bağımsız etkisini ortaya koyabilmek için, bu kişilerden elde edilen 1477 anket sonucu çok değişkenli analiz ile incelendi.

Bulgular: Sonuçlarımız; çocuk hekimi olmanın, tıp fakültesinde çalışmanın ve fizik muayene için yeterli vakit ayırmanın bağımsız olarak az antibiyotik reçete edilmesi ile ilişkili olduğunu gösterdi. Aile hekimi ve pratisyen hekimler çocuklarda üst solunum yolu enfeksiyonları için daha fazla antibiyotik yazmaktaydılar.

Sonuç: Çocuklarda üst solunum yolu enfeksiyonlarında antibiyotik reçete etme davranışını düzenleyen en önemli faktörler fizik muayene süresi ve eğitimin kalitesiydi. (Güncel Pediatri 2013; 11: 45-50)

Anahtar kelimeler: Aile hekimi, antibiyotik, çocuk hekimi, pratisyen hekim, üst solunum yolu enfeksiyonu

\section{SUMMARY}

Introduction: In order to guide the improvement in the national judicious antibiotic use policy, the socio-cultural, socio-demographic, and cognitive factors that may potentially influence the prescribing habits of pediatricians, family physicians and general practitioners to upper respiratory tract infections in children were investigated.

Materials and Methods: After receiving approval from ethic committee, questionnaire was sent to 7421 physicians who had been practicing in the different regions of the country. Responses obtained from 1477 of them were evaluated by multivariate analysis to demonstrate independent effect of each factor influencing the prescribing habits.

Results: Our results have shown that being a pediatrician, working in medical school, and spending enough time for physical examination were independently associated with less antibiotic prescription. Family physicians and general practitioners were more likely to prescribe antibiotics for viral upper respiratory infections in children.

Conclusions: The most important modifying factors about antibiotic prescription habits for upper respiratory tract infections in children were physical examination period and quality of education. (Journal of Current Pediatrics 2013; 11: 45-50)

Key words: Antibiotic, family physician, general practitioner, pediatrician, upper respiratory tract infection 


\section{Giriş}

Antibiyotiklerin keşfi ile bakteriyel enfeksiyonlara bağlı komplikasyon ve ölüm oranlarının azalması antibiyotiklerin tüm dünyada yaygın ve uygunsuz kullanılmasına neden oldu (1). Bunun neticesinde ise dirençli mikroorganizmaların yaygınlaşmasına bağlı olarak enfeksiyonların tedavi edilmesinde güçlükler yaşanmaya başladı $(2,4)$. Hastalar antibiyotik kullanımına bağı ciddi yan etkilere maruz kaldılar (5) ve sağlık harcamalarında belirgin artışlar gözlendi $(6,7)$. Günümüzde dirençli mikroorganizmalara bağlı toplum kaynaklı enfeksiyonlar halk sağlığını önemli ölçüde tehdit etmektedir (8). Bu tehdide yönelik farkındalık araștırmacıları hekimlerin antibiyotik davranışlarını etkileyen faktörleri inceleyerek akılcı antibiyotik kullanım davranışlarını geliştirmeye itmektedir.

Çocuk yaş grubu hastaların poliklinik bașvurularının önemli bir bölümünü üst solunum yolu enfeksiyonları (ÜSYE) oluşturmakta ve çoğu antibiyotik reçete edilmesi ile sonlanmaktadır (9). Reçete alışkanlıklarının ilaç endüstrisi, hasta ve doktor üçgeni etkileşiminde sosyokültürel, sosyodemografik, ekonomik ve düşünsel faktörlere bağlı şekillenmekte olduğu belirtilmektedir $(1,10,11)$. Çalışmamızda bu faktörlerin Türk hekimlerinin çocuk yaş grubu hastalarda ÜSYE tedavisi için antibiyotik reçete etme davranışları üzerine etkisi olup olmadığını anket yolu ile araştırmayı amaçladık ve Türkiye'nin çeşitli bölgelerinde çalışan çocuk hekimleri, aile hekimleri ve pratisyen hekimler hedef grubumuzu oluşturdu.

\section{Gereç ve Yöntem}

\section{Veri Toplama ve Çalışma Grubu}

Hekimlerin adresleri ulusal pediatri, aile hekimleri ve pratisyen hekim dernekleri ve tabip odalarından elde edildi. Etik kurul onayı alındıktan sonra anketler coğrafik dağılım göz önüne alınarak 3710'u pratisyen hekim (\%50), 964'ü aile hekimi (\%13) ve 2745 'i çocuk sağlığı ve hastalıkları hekimi (\%37) olmak üzere toplam 7421 hekime posta ve/ veya elektronik-posta yolu ile dağıtıldı. Günlük baktıkları çocuk yaş grubu hastaların oranı \%25'in altında olan aile hekimi ve pratisyen hekimlerin anketi yanitlamamaları istendi. Anket sorularını hekimlerin karakteristik özellikleri ve çocuk yaş grubu hastalarda ÜSYE için günlük antibiyotik yazma davranışlarını gösteren çoktan seçmeli sorular oluşturdu.

\section{Istatistiksel Analiz}

Tüm veriler Microsoft Excel ${ }^{\circledR}$ veri tabanına kaydedildi. Çocuk yaş grubu hastalarda ÜSYE için yüksek oranda antibiyotik reçete edilmesine neden olan olası faktörler (bağımsız değişkenler) incelendi. Çocuklarda görülen ÜSYE için günlük antibiyotik reçete etme oranı $\% 50$ 'nin üzerinde ise "antibiyotik reçete etme oranı yüksek" kabul edildi (12). Bağımsız değişkenleri; 1) cinsiyet, 2) pratisyen hekim, aile hekimi veya çocuk sağlığı ve hastalıkları uzmanlıkları, 3) çalışılan kurum, 4) 10 yılın altında hekimlik yapma, 5) 10 dakikanın altında fizik muayene süresi ayırma parametreleri oluşturdu. Istatistiksel analiz için Stata program v. 9,2 (Stata Corp LP, Texas) kullanıldı. Demografik veriler oran, ortalama \pm standart sapma veya ortanca (minimum-maksimum) olarak ifade edildi. Bağımlı ve bağımsız değişkenler tek değişkenli analizde ki-kare ve Fisher kesin olasılık testi kullanılarak karşılaştırıldı. Bağımsız risk faktörlerin belirlenmesi için basamaklı geriye doğru lojistik regresyon analizi kullanıldı. Tek değişkenli analizde $p$ değeri 0,2'nin altında olan değişkenler nesne sayısı $\leq 10$ değil ise çok değişkenli analize dâhil edildi. Eş paralellik gösteren parametreler çıkartıldıktan sonra analizler tekrar edildi. Sonuçlar tahmini rölatif risk [(odds oranı) $(\mathrm{OR})$ ] ve \%95 güven aralığı (GA) şeklinde ifade edildi. Lojistik regresyonun son modelinde anlamlı bulunan parametrelere tablolarda yer verildi. $P$ değeri 0,05 'in altında ise anlamlı kabul edildi.

\section{Bulgular}

Anketlere yanıt oranı \%19'du (7421 hekimin 1493'ü). Beş katılımcı uzun emeklilik süreleri nedeniyle, 11 katıı ımcı anketi eksik bırakmaları nedeniyle çalışmadan çıkartıldı. Geriye kalan 1477 hekimin özelikleri ve tek değişkenli analiz sonuçları Tablo 1'de gösterildi. Katılımcıların \%14,96'sı ( $n=221)$ pediatri asistanı, \%25,73'ü $(n=380)$ pediatri uzmanı, \%16,38'i $(n=242)$ aile hekimi, \%42,92'si $(n=634)$ pratisyen hekimdi (Tablo 1). Hekimler tarafından belirtilen günlük bakılan çocuk yaş grubu hasta sayısı için ortanca değer 33 (6-200) idi.

Tek değişkenli analiz sonuçlarına göre pediatri uzmanı olmak, üniversite veya özel hastanede çalışmak çocuk yaş grubu hastalarda ÜSYE için "günlük $\leq \% 50$ antibiyotik reçete etme" ile ilişkili iken; aile hekimi veya pratisyen hekim olmak, devlet hastanesi veya sağlık ocağında çalışmak ve fizik muayene süresini kısa tutmak ( $<10 \mathrm{dk}$ ) "günlük $>\% 50$ antibiyotik reçete etme" ile ilişkili idi (Tablo 2).

Çok değişkenli analiz sonuçları ise üniversitede hekimlik yapmanın (OR: 0,53; GA:0,34-0,82; $p=0,005$ ), hastaya uzun fizik muayene süresi ayırmanın (OR:0,51; GA:0,37$0,69 ; p<0,0001)$ ve çocuk hekimi olmanın (OR:0,71; $\mathrm{GA}: 0,51-0,98 ; p=0,038)$ bağımsız olarak çocuk yaş 


\begin{tabular}{|c|c|c|}
\hline Hekimlerin özellikleri & $\mathrm{n}$ & $\%$ \\
\hline \multicolumn{3}{|l|}{ Cinsiyet } \\
\hline Erkek & 729 & 49,36 \\
\hline Kadın & 748 & 50,64 \\
\hline \multicolumn{3}{|l|}{ Hekimlik süresi (yıl) } \\
\hline$<10$ yll & 706 & 48,99 \\
\hline$>10 \mathrm{yll}$ & 735 & 51,01 \\
\hline \multicolumn{3}{|l|}{ Uzmanlık } \\
\hline Çocuk sağılğı ve hastalıkları asistanı & 221 & 14,96 \\
\hline Çocuk sağlığı ve hastalıkları uzmanı & 380 & 25,73 \\
\hline Aile hekimi & 242 & 16,38 \\
\hline Pratisyen hekim & 634 & 42,92 \\
\hline \multicolumn{3}{|l|}{ Çalışılan kurum } \\
\hline Devlet hastanesi & 175 & 11,90 \\
\hline Eğitim ve araştırma hastanesi & 323 & 21,97 \\
\hline Üniversite hastanesi & 196 & 13,33 \\
\hline Özel muayenehane & 38 & 2,59 \\
\hline Özel hastane & 128 & 8,71 \\
\hline Sağlık ocağı & 536 & 36,46 \\
\hline Devlet hastanesi ve özel muayenehane & 44 & 2,99 \\
\hline Diğer $\ddagger$ & 30 & 2,04 \\
\hline \multicolumn{3}{|l|}{ Hasta başına ayrılan fizik muayene süresi } \\
\hline$>10$ dakika & 981 & 67,52 \\
\hline$<10$ dakika & 472 & 32,48 \\
\hline \multicolumn{3}{|l|}{ Günlük antibiyotik reçete etme oranı } \\
\hline$<\% 50$ & 890 & 65,73 \\
\hline$>\% 50$ & 464 & 34,27 \\
\hline \multicolumn{3}{|l|}{ ‡Verem savaş dispanseri, kampüs poliklinikleri } \\
\hline
\end{tabular}

grubu hastalarda ÜSYE için az antibiyotik reçete edilmesi ile ilişkili olduğunu göstermekte idi (Tablo 3).

\section{Tartıșma}

Antibiyotiklerin yaygın olarak kullanılması tüm dünyada antimikrobiyal direncin yaygınlaşması ile sonuçlanmakta; yeni antibiyotiklerin sınırlı sayıda keşfi ise araştırmacıları hekimlerin antibiyotik reçete etme davranışlarını araştırmaya ve akılcı antibiyotik kullanım davranışlarını geliştirmeye itmektedir. Gelişmiş ülkelerde üst solunum yolu hastalıklarına yönelik akılcı antibiyotik kullanımını belirleyen sayısız klinik rehber basılmaktadır (13-16).
Gelişmekte olan ülkelerde ise toplumdan kazanılan enfeksiyonlara yönelik gereksiz antibiyotik kullanımını araştıran çalışma sayısı sınırlı kalmaktadır (1,17-19). Ülkeden ülkeye sosyoekonomikve sosyokültürel özelliklerin değişkenlik göstermesi, akılcı antibiyotik kullanımının önündeki engelleri belirlemek adına her bir ülkenin kendi hekim davranışlarını incelemesini gerektirmektedir. Ülke genelinde yapılan bu anketin sonuçları göstermektedir ki çocuk yaş grubu hastalarda ÜSYE için antibiyotik yazılmasını etkileyen en önemli faktörler hastaya ayrılan süre ve hekimlerin eğitim içerikleridir.

Yurtdışında yapıımış olan çalışmalar hastaya ayrılan poliklinik muayene süresinin ÜSYE için antibiyotik reçete edilmesini önemli ölçüde etkilediğini göstermektedir $(20,21)$. Türkiye'de 31978 pratisyen hekim, 4025 çocuk hekimi ve 1541 aile hekimi çalışmaktadır (22). Hekim başına düşen hasta sayısı pratisyen hekimler için 2269, çocuk hekimleri için 18181 ve aile hekimi uzmanları için 47169'dur (22). Karşıllaştırma yapııdığında Türkiye'de her 100.000 hasta başına düşen pratisyen hekim oranının Avrupa ülkelerinin yarısı kadar olduğu görülmektedir (22). Türkiye'de 2009 verilerine göre kişi başına düşen yıllık doktora başvuru sayısı ortalamada 7 iken bu oran "Organization for Economic Co-operation and Development" (OECD) ülkelerinde 6, Yunanistan ve ABD de ise 4'tür (23). Bu mevcut hasta yükü her bir hastaya ayrılan fizik muayene süresinin azalması ile sonuçlanmaktadır. Bizim çalışmamızın sonuçları da fazla hasta yükü ile karakterize olan devlet hastanelerinde çalışmanın ve fizik muayene süresini kısa tutmanın çocuk yaş grubu hastalarda ÜSYE için akılcı antibiyotik reçete etmenin önündeki temel engeller olduğunu desteklemektedir (Tablo 2).

Çalışmamızın sonucunda üniversite hastanesinde çalışmanın diğer faktörlerden bağımsız olarak çocuk yaş grubu hastalarda görülen ÜSYE için az antibiyotik reçete etmekle ilişkili olduğu sonucuna varılmıştır (Tablo 3). Bu durum antibiyotik reçete etme davranışları üzerinde eğitime daha fazla süre ayrılan bir kurumda çalışmanın etkisi ile açıklanabilir.

OECD üyesi çeşitli ülkelerde son iki dekatta sağlık hizmetinde performans sistemi uygulanmaktadır (24). Türkiye'de bu sisteme sağlık bakanlığına bağı hastanelerde 2004, üniversite hastanelerinde 2011 yılında geçilmiştir. Bu sistemde hekim ücretlerini hekimlerin poliklinikte baktığı hasta sayıları, konsültasyonlar ve uyguladıkları girişimler belirlemektedir. Tabip odası 2008 yılında hekimlere uyguladığı ve 1469 hekimin yanıtladığı anket soruları ile hekimlerin performans sistemini değerlendirmesine aracı olmuştur (25). Hekimlerin \%63,8'i tetkik, \%46,3'ü yoğun 


\begin{tabular}{|c|c|c|c|c|}
\hline & \multicolumn{2}{|c|}{$\begin{array}{l}\text { Günlük antibiyotik reçete etme } \\
\qquad>\% 50\end{array}$} & \multirow[b]{2}{*}{ OR (\%95 GA) } & \multirow[b]{2}{*}{$P$} \\
\hline & $n$ & $\%$ & & \\
\hline \multicolumn{5}{|l|}{ Cinsiyet } \\
\hline $\begin{array}{l}\text { Erkek } \\
\text { Kadın }\end{array}$ & $\begin{array}{l}233 \\
231\end{array}$ & \begin{tabular}{|l|}
34,42 \\
34,12
\end{tabular} & $1,01(0,80-1,27)$ & 0,9 \\
\hline \multicolumn{5}{|l|}{ Hekimlik süresi (yıl) } \\
\hline $\begin{array}{l}\geq 10 \mathrm{yll} \\
<10 \mathrm{yll}\end{array}$ & $\begin{array}{l}214 \\
238\end{array}$ & \begin{tabular}{|l|}
31,33 \\
37,56
\end{tabular} & $0,75(0,60-0,95)$ & 0,01 \\
\hline \multicolumn{5}{|l|}{ Uzmanlik } \\
\hline $\begin{array}{l}\text { Pediatri asistanı } \\
\text { Diğer hekimler }\end{array}$ & $\begin{array}{l}67 \\
397\end{array}$ & $\begin{array}{l}32 \\
34\end{array}$ & $0,88(0,63-1,22)$ & 0,4 \\
\hline $\begin{array}{l}\text { Pediatri uzmanı } \\
\text { Diğer hekimler }\end{array}$ & $\begin{array}{l}89 \\
375\end{array}$ & $\begin{array}{l}24 \\
38\end{array}$ & $0,51(0,39-0,68)$ & $<0,0001$ \\
\hline $\begin{array}{l}\text { Aile hekimi } \\
\text { Diğer hekimler }\end{array}$ & $\begin{array}{l}84 \\
378\end{array}$ & \begin{tabular}{|l|}
42 \\
32.93
\end{tabular} & $1,47(1,07-2,02)$ & 0,01 \\
\hline $\begin{array}{l}\text { Pratisyen hekim } \\
\text { Diğer hekimler }\end{array}$ & $\begin{array}{l}224 \\
240\end{array}$ & $\begin{array}{l}38,82 \\
30.89\end{array}$ & $1,41(1,12-1,79)$ & 0,002 \\
\hline \multicolumn{5}{|l|}{ Çalışılan kurum } \\
\hline $\begin{array}{l}\text { Devlet hastanesi } \\
\text { Diğer kurumlar }\end{array}$ & \begin{tabular}{|l|}
71 \\
391
\end{tabular} & $\begin{array}{l}43,29 \\
32.97\end{array}$ & $1,55(1,09-2,19)$ & 0,009 \\
\hline $\begin{array}{l}\text { Eğitim-Araşırıma hastanesi } \\
\text { Diğer kurumlar }\end{array}$ & $\begin{array}{l}143 \\
319\end{array}$ & $\begin{array}{l}31,02 \\
35,88\end{array}$ & $0,8(0,62-1,02)$ & 0,07 \\
\hline $\begin{array}{l}\text { Üniversite hastanesi } \\
\text { Diğer kurumlar }\end{array}$ & $\begin{array}{l}31 \\
431\end{array}$ & $\begin{array}{l}17,42 \\
36.77\end{array}$ & $0,36(0,23-0,54)$ & $<0,001$ \\
\hline $\begin{array}{l}\text { Özel hastane } \\
\text { Diğer kurumlar }\end{array}$ & \begin{tabular}{|l|}
31 \\
431
\end{tabular} & $\begin{array}{l}25,00 \\
35.15\end{array}$ & $0,61(0,38-0,95)$ & $<0,001$ \\
\hline $\begin{array}{l}\text { Sağllk ocağı } \\
\text { Diğer kurumlar }\end{array}$ & $\begin{array}{l}189 \\
273\end{array}$ & $\begin{array}{l}37,72 \\
32.16\end{array}$ & $1,27(1,00-1,62)$ & 0,03 \\
\hline \multicolumn{5}{|c|}{ Hasta başına ayrılan fizik muayene süresi (dk) } \\
\hline $\begin{array}{l}>10 \text { dakika } \\
<10 \text { dakika }\end{array}$ & $\begin{array}{l}92 \\
372\end{array}$ & $\begin{array}{l}20,8 \\
41\end{array}$ & $0,36(0,21-0,53)$ & $<0,0001$ \\
\hline
\end{tabular}

bakım ünitesine yatış, \%44,7'si konsültasyon, \%64,4'ü endikasyon dışı girişim, \%70'i etik kurallar dışında gerçekleşen uygulama ve \%52,'si hatalı tedavi oranlarının arttığını ve \%67,3'ü hasta başına düşen fizik muayene süresinin performans sisteminin uygulamaya girdiği 2004 yıından itibaren giderek azaldığını ifade etmişlerdir (25). Bu ankette ayrıca, hekimlerin çoğu (ortalama $\% 65$ 'i) mezuniyet sonrası eğitimlerinin de olumsuz yönde etkilendiğini belirtmişlerdir (25). Yurtdışında yapılan araştırmalarda hekimlerin performansa dayalı ödeme sistemine yönelik taşıdığı en temel kaygının kaliteli sağlık hizmetini engellemesi olduğunu göstermektedir (26). Bu sonuçlardan yola çıkılarak performans sisteminin antibiyotikleri de içeren ilaç reçete etme oranları üzerinde anlamlı bir etkisi olduğu çıkarımı yapılabilir.

Çalışmamızın sonuçlarını yorumlarken dikkat edilmesi gereken bazı hususlar bulunduğunu düşünmekteyiz. Öncelikle çalışmanın anket niteliğinde olması hatırlamaya 


\begin{tabular}{|l|l|l|l|}
\hline \multicolumn{4}{|c|}{$\begin{array}{l}\text { Tablo 3. Cocuklarda görülen ÜSYE için antibiyotik reçete } \\
\text { edilmesini etkileyen faktörlerin çok değişkenli analiz sonuçları }\end{array}$} \\
\hline $\begin{array}{l}\text { Fazla antibiyotik reçete etme } \\
\text { ile ilişkili faktörler }\end{array}$ & OR & \%95 GA & P \\
\hline Üniversite hastanesi & 0,53 & $0,34-0,82$ & 0,005 \\
\hline Pediatri uzmanı & 0,71 & $0,51-0,98$ & 0,038 \\
\hline $\begin{array}{l}\text { Hasta başına ayrllan muayene } \\
\text { süresi }>10 \text { dk }\end{array}$ & 0,51 & $0,37-0,69$ & $<0,001$ \\
\hline
\end{tabular}

dayalı önyargıyı olası kılmaktadır, ancak hekimlerin günlük uygulamalarını ve davranışlarını belgelemekte yaşanan güçlükler araştırmacıları bu konuda anket çalışması gibi daha az hassas olan ve daha dikkatli yorumlamayı gerektiren yöntemleri kullanmaya itmektedir $(5,9,27,28)$. Bunun dışında anket çalışmamıza yanıt oranı sadece \%19'dur. Bu düşük oran hekimlerin çağımızın en önemli sağlık problemlerinden biri olan antimikrobiyal direncin yaygınlaşmasını ve bu nedenle de akılcı olmayan antibiyotik kullanım davranışlarının irdelenmesini yeterince önemsemediklerini düşündürmektedir. Performans sisteminin getirisi ile artan hasta yoğunluğu içerisinde hekimler anket sorularını yanıtlamaya vakit ayırmamış olabilirler. Yanıtlanmamış anketlerin ise sonuçları ne şekilde etkileyeceği öngörülememektedir. Uygun olmayan tedavi davranışı sergilemeyi tercih eden hekimler soruları doğru yanıtı verecek şekilde günlük davranışlarının aksi yönde yanitlamış olabilirler, ancak bu ikilem tüm anket çalışmaları için geçerli olmaktadır $(5,9,27,28)$. Bu konuda yapılan çeşitli çalışmalarda bağımlı değişken farklıık gösterebilmektedir ki biz çalışmamızda bağımlı değişkeni çocuklarda görülen ÜSYE'de günlük antibiyotik reçete etme oranı $\geq \% 50$ veya $<\% 50$ olarak belirlemeyi tercih ettik $(5,8,9)$. Bu rakamı belirlerken çeşitli ülkelerden bildirilen USYE tedavisi için antibiyotik reçete etme oranlarından faydalandık. ABD'de olduğu gibi Asya-Pasifikülkelerinde de birinci basamak sağlık hizmeti verilen kuruluşlarda çocuk hastalarda ÜSYE tedavisi için \%11,6 ila \%67 arasında antibiyotik reçete edildiği ifade edilmektedir (12,29-31). Nitekim çalışmamıza katılan hekimlerin \%34,27'si çocuk yaş grubu hastalarda ÜSYE tedavisinde $\% 50$ 'den daha fazla oranda antibiyotik reçete ettiğini ifade etmişlerdir.

Sonuç olarak çalışmamızda fizik muayene için yeterli süre ayırmanın ve eğitim ağırlıklı sağlık uygulamalarının çocuk yaş grubu hastalarda üst solunum yolu enfeksiyonlarında antibiyotik reçete etme davranışını belirleyen en önemli faktörler olduğu sonucuna varıldı.

\section{Kaynaklar}

1. Teng CL, Achike Fl, Phua KL, Norhayati Y, Nurjahan MI, Nor AH, Koh CN, et al. General and URTI-specific antibiotic prescription rates in a Malaysian primary care setting. Int $\mathrm{J}$ Antimicrob Agents 2004;24:496-501.
2. Nicolau D. Clinical and economic implications of antimicrobial resistance for the management of community-acquired respiratory tract infections. I Antimicrob Chemother 2002;50:61-70.

3. Johnston BL. Methicillin-resistant Staphylococcus aureus as a cause of community-acquired pneumonia--a critical review. Semin Respir Infect 1994;9:199-206.

4. Levy I, Leibovici L, Drucker M, Samra Z, Konisberger H, Ashkenazi S. A prospective study of Gram-negative bacteremia in children. Pediatr Infect Dis J 1996;15:117-22.

5. Cunha BA. Effective antibiotic-resistance control strategies. Lancet 2001;357:1307-8.

6. Mainous AG 3rd, Hueston WJ, Clark JR. Antibiotics and upper respiratory infection: do some folks think there is a cure for the common cold. J Fam Pract 1996;42:357-61.

7. Rao N, Jacobs S, Joyce L. Cost-effective eradication of an outbreak of methicillin-resistant Staphylococcus aureus in a community teaching hospital. Infect Control Hosp Epidemiol 1988;9:255-60.

8. Corbett KK, Gonzales R, Leeman-Castillo BA, Flores E, Maselli $\mathrm{J}$, Kafadar K. Appropriate antibiotic use: variation in knowledge and awareness by Hispanic ethnicity and language. Prev Med 2005;40:162-9.

9. Chang GC, Tang SF. Parental knowledge, attitudes and antibiotic use for acute upper respiratory tract infection in children attending a primary healthcare clinic in Malaysia. Singapore Med J 2006;47:266-70.

10. Okeke IN, Lamikanra A, Edelman R. Socioeconomic and behavioral factors leading to acquired bacterial resistance to antibiotics in developing countries. Emerg Infect Dis 1999;5:18-27.

11. Avorn J, Solomon DH. Cultural and economic factors that (mis)shape antibiotic use: the nonpharmacologic basis of therapeutics. Ann Intern Med 2000;133:128-35.

12. Simpson SA, Wood F, Butler CC. General practitioners' perceptions of antimicrobial resistance: a qualitative study. J Antimicrob Chemother 2006;59:292-6.

13. Irwin RS, Baumann MH, Bolser DC, Boulet LP, Braman SS, Brightling $\mathrm{CE}$, et al. Diagnosis and management of cough executive summary: ACCP evidence-based clinical practice guidelines. Chest 2006;129 (Suppl 1):1-23.

14. Diagnosis and Management of Acute Otitis Media. Subcommittee on Management of Acute Otitis Media: Diagnosis and management of acute otitis media (editorial). Pediatrics 2004;113:1451-65.

15. Wong DM, Blumberg DA, Lowe LG. Guidelines for the use of antibiotics in acute upper respiratory tract infections. Am Fam Physician 2006;74:956-66.

16. Centre for Clinical Practice. Respiratory tract infections antibiotic prescribing. Prescribing of antibiotics for self-limiting respiratory tract infections in adults and children in primary care (editorial). London (UK): National Institute for Health and Clinical Excellence (NICE); 2008.

17. Stojanovi-Spehar S, Blazekovi-Milakovi S, Bergman-Markovi B, Vrca-Botica M, Matijasevi I. Prescribing antibiotics to preschool children in primary health care in Croatia. Coll Antropol 2008;32:125-30.

18. Sahin H, Arsu G, Köseli D, Büke C. Evaluation of primary health care physicians' knowledge on rational antibiotic use. Mikrobiyol Bul 2008;42:343-8. 
19. Kho BP, Ong CM, Tan FT, Wee CY. Antibiotic prescribing for upper respiratory tract infections in sarawak district hospitals. Med J Malaysia 2013;68:136-40.

20. Bauchner H, Pelton SI, Klein JO. Parents, physicians, and antibiotic use. Pediatrics 1999;103:395-8.

21. Linder JA, Singer DE, Stafford RS. Association between antibiotic prescribing and visit duration in adults with upper respiratory tract infections. Clin Ther 2003;25:2419-30.

22. Turkiye'de saglik egitimi ve saglik insan gucu durum raporu, Ankara 2010:1-281.

23. Turkiye saglik sektoru raporu. Yased. Haziran 2012:27. http:// www.yased.org.tr.

24. Marsden D. Perspectives on performance pay in government organizations: a short review of history, research and theory so far, and main trends in OECD member countries. Introductory paper for the OECD-GOV/PUMA experts meeting. Performance-related pay of government employees: Assesing reforms across OECD countries, experts meeting, OECD, Paris 2003.
25. Hekimlerin degerlendirmesi ile performansa dayali odeme. Turk Tabipleri Birligi Etik Kurulu, Ankara 2009:1-64.

26. Armour BS, Pitts MM, Maclean R, Cangialose C, Kishel M, Imai $\mathrm{H}$, et al. The effect of explicit financial incentives on physician behavior. Arch Intern Med 2001;161:1261-6.

27. Simpson SA, Wood F, Butler CC. General practitioners' perceptions of antimicrobial resistance: a qualitative study. $\mathrm{J}$ Antimicrob Chemother 2006;59:292-6.

28. Huang N, Morlock L, Lee CH, Chen LS, Chou YJ Antibiotic prescribing for children with nasopharyngitis (common colds), upper respiratory infections, and bronchitis who have healthprofessional parents. Pediatrics 2005;116:826-32.

29. Lim KHJ, Yap KB. The prescribing pattern of outpatient polyclinic doctors. Singapore Med J 1999;40:416-9.

30. Chang SC, Shiu MN, Chen TJ. Antibiotic usage in primary care units inTaiwan after the institution of national health insurance. Diagn Microbiol Infect Dis 2001;40:137-43.

31. Chalker J. Improving antibiotic prescribing in Hai Phong Province, Vietnam: the 'antibiotic-dose' indicator. Bull World Health Organ 2001;79:313-20.

\section{Ek-1}

HEKIMLERIN RUTIN UYGULAMADA ÇOCUK YAŞ GRUBU HASTALAR IÇIN AYAKTAN ANTIBBIYOTIK KULLANIMI ILE ILGILI YAKLAŞIMLARININ INCELENMESI
1) Cinsiyetiniz
$\neg$ Kadın
$\neg$ Erkek

2) Kaç yıldır doktorluk yapıyorsunuz?

3) Uzmanlık alanınız $\square$ Pediatri asistanı

4) Çalıştığınız il $\square$ lstanbul

$\neg$ Pediatri uzmanı

$\neg$ Ankara

$\neg$ Özel muayenehane $\neg$ Pratisyen

$\neg$ Diğer.......

$\neg$ Özel hastane / poliklinik

$$
\square \text { Tıp fakültesi } \square \text { Sağllkk ocağı }
$$

6) Günde yaklaşık kaç çocuk hasta muayene ediyorsunuz? Rutin baktığınız hastaların yüzde kaçı çocuk yaş grubundadır?

Ilkbahar / Yaz $\%$. Sonbahar / KIş. $\%$

7) Bir hastaya ilk başvurusunda ortalama kaç dakika zaman ayırıyorsunuz?

$\neg 5 \mathrm{dk}$ 'dan az

$\neg 5-10 \mathrm{dk}$

$\neg 10-20 \mathrm{dk}$

$\neg 20$ dk'dan daha fazla

8) Günde muayene ettiğiniz çocuk yaş grubu hastaların yaklaşık yüzde kaçına oral veya parenteral antibiyotik reçete ediyorsunuz? 